\title{
Effect of Conditioned and Co Culture Media from The Umbilical Cord Mesenchymal Stem Cells on Heptoma Cell Line (Huh7)
}

\author{
Marwa. M. Hussein*, Swelim. H. H, Hanaa A. Amer, Fatma A. Abu Zahra, Mourad M. Hadier \\ Department of Zoology, Faculty of Science- Ain Shams University \\ *Corresponding author: Marwa. M. Hussein, Mobile: (+20)01210103878, E-mail: marwasoada@ yahoo.com
}

\begin{abstract}
Background: this study aimed to detect a new way for cancer control. Hepatoma cell line HuH7 was the model for cancer and was treated with two types of the media. The first was the conditioned media (in which mesenchymal stem cells were cultured), the second media was co-culture media in which mesenchymal stem cells and HuH7 cells were cultured. Objective: this work was designed to evaluate the efficiency of using the media in which mesenchymal stem cells alone (Conditioned media) or co-culture with $\mathrm{HuH7}$ (Co-cultured media) were housed on controlling the viability, growth and mortality of $\mathrm{HuH7}$, by applying different techniques. Result: at specified times $(0,48,72,96$ hours) after incubation in each medium cells were tested. The morphological study showed that in both conditioned and co-culture media, HuH7 cells were suffered from damage and this was directly proportional with increase of time. (3-(4, 5-dimethylthiazol-2-yl)-2, 5-diphenyltetrazolium bromide) tetrazolium reduction assay (MTT) showed that there was a significant difference between the four groups in conditioned and co-culture media. In the biochemical study for conditioned and co-culture media, there was a significant difference between the four groups in $\alpha \mathrm{FP}$ and GOT, but there was a non-significant difference between the four groups in albumin, GPT, ALP and $\gamma$-GT. Conclusion: the conditioned and co-culture media from mesenchymal stem cells alone or co-culture with $\mathrm{HuH} 7$ proved to be efficient in control of cancer cell survival.
\end{abstract}

Key words: hepatoma cell line (HuH7), Umbilical cord Mesenchymal Stem Cell (UMSC), proliferating cell nuclear antigen (PCNA) and Vascular Endothelial Growth Factor (VEGF).

\section{INTRODUCTION}

Hepatocellular carcinoma (HCC) is the most common primary malignancy of the liver. It is the $5^{\text {th }}$ most common cancer in men, worldwide, and $7^{\text {th }}$ among women, with over half a million new cases diagnosed annually worldwide. It is the second leading cause of cancer related mortality in the world (1). Egypt has the highest prevalence of HCV in the world (predominantly genotype 4), Up to $60 \%$, have been reported in older individuals, in rural areas such as the Nile Delta and in the lower social classes ${ }^{(2)}$. In Egypt, HCC was reported to account for about $4.7 \%$ of chronic liver disease (CLD) patients. $\mathrm{HCC}$ has been recorded to be the commonest cancer in the Egyptians $(23.8 \%)$, but a higher level was reported in males (33.6\%) than females (13.5\%). Different liver diseases can be treated by using stem cells like liver cirrhosis, genetic liver diseases and liver necrosis ${ }^{(4)}$. In response to liver injury or loss of liver mass, proliferation of mature liver cells is the first-line defense to restore liver homeostasis ${ }^{(5)}$. Mesenchymal stem cells (MSCs) play several simultaneous roles to limit inflammation through releasing cytokines, aiding healing by expression of growth factors ${ }^{(5)}$.

\section{METHODS}

Ethical approval:

The study was approved by the Ethical approval was granted by Ethics and Research Committee of the Medicine Ain Shams Research Institute (MASRI), Faculty of Medicine, Ain Shams University.

\section{Mesenchymal Stem Cells (MSCs)}

Mesenchymal stem cells from umbilical cords $(\mathrm{n}=11$; gestational ages, 39,40 weeks) were collected, obtained from consenting patients with a surgeon, and processed within 2-3 hours after caesarean births attending The Women's Hospitals and Obstetrics of Ain Shams University. These samples were collected from the $1^{\text {st }}$ of October 2013 to the $1^{\text {st }}$ of March 2016. 2. Isolation of MSCs from Umbilical Cord (UC)

UCs were washed with Dulbecco's PBS for several times, cut to small pieces and filled with $0.1 \%$ collagenase type $\Pi$ for cell digestion (Sigma-Aldrich, St. Louis) in phosphate buffer saline (PBS) and shacked in water bath at $37^{\circ} \mathrm{C}$ for $60 \mathrm{~min}$. Each UC was washed with proliferation medium and the detached cells were harvested after gentle massage of the UC. Cells were centrifuged at $300 \mathrm{~g}$ for $10 \mathrm{~min}$, re-suspended in proliferation medium and seeded in $25-\mathrm{cm} 2$ flasks at a density of $5 \times 10^{5}$ cells per $\mathrm{ml}$. After $72 \mathrm{hrs}$ of incubation, non-adherent cells were removed and culture medium was replaced every 3 days. On day 14 , the adherent colonies of cells were removed by using trypsin EDTA, and counted. Cells were identified as being MSCs by their morphology, adherence, and their power to differentiate into osteocytes and neurocytes.

3. Identification of UC-MSC by flow cytometer The UC-MSC were digested and stained with antiCD44- fluorescein isothiocyanate (FITC), anti-CD34FITC, anti-CD105and FITC, anti-CD19-FITC, (Becton Dickinson, Franklin Lakes, NJ, USA) or the isotype monoclonal antibody (mAb). The cells were collected by using FACS Calibur (Becton Dickinson, 
San Jose, CA, USA); the data were analyzed by FlowJo software (TreeStar, Ashand, OR, USA ).

\section{Culture of human hepatoma (HuH7) cells}

Human Hepatoma (HuH7) cells were obtained from Vacsera (Japanese male type cultollection) and they were grown in a sterile $75-\mathrm{cm} 2$ tissue culture flask in complete medium containing DMEM supplemented with 10\% FBS, $1.5 \%$ antibiotics (penicillin / streptomycin) and $0.05 \%$ of fungizone (antifungal) $95 \%$ air $/ 5 \% \mathrm{CO} 2$ at $37^{\circ} \mathrm{C}$. Cells were cultured to $100 \%$ confluence. Cells from passage 14 were used in this study.

\section{Treatment of HuH7 with mesenchymal stem cells conditioned media}

Human MSCs were cultured as described above. At the proper time of experiment $\left(4^{\text {th }}\right.$ passage of MSCs) the media were collected from the flasks and served as MSC conditioned media. $\mathrm{HuH7}$ cells were treated with a mixture of complete medium containing DMEM supplemented with 10\% FBS, antibiotics (penicillin/ streptomycin), fungizone and hMSCs conditioned medium (1:1) for 0-48-72-96 hrs, and the culture medium was replaced every $24 \mathrm{hrs}$.

\section{Treatment of $\mathrm{HuH} 7$ with co-culture conditioned media}

HuH7 cells were treated with co-culture conditioned media for 48-72-96 hrs, and the culture media were replaced every $24 \mathrm{hrs}$.

Preparation of co-culture conditioned media: the growth medium of cultured HuH7cells was removed and adherent cells were washed twice with 1X PBS and detached by trypsin $(2.5 \mathrm{~g} / \mathrm{L}) / \mathrm{EDTA}(1 \mathrm{~g} / \mathrm{L})$ for 5 $10 \mathrm{~min}$ at $37^{\circ} \mathrm{C}$. Cells were centrifuged at $1500 \mathrm{rpm}$ for $5-10 \mathrm{~min}$, at $17^{\circ} \mathrm{C}$. The cell suspension $(\mathrm{HuH7})$ was added to the cultured MSCs. So, the co-culture medium was composed of DMEM (lonza) supplemented with $10 \%$ fetal bovine serum and antibiotics penicillin / streptomycin, and fungizone. The ratio of MSCs: HuH7 cells was 1:1 and cells were co-cultured for $72 \mathrm{hrs}$. At that time, the media were collected from the flasks and were used as hMSCs and HuH7 co-culture conditioned media.

\section{MTT Tetrazolium Assay Concept (MTT Assay)}

$\mathrm{HuH} 7$ treated with MSC conditioned media and $\mathrm{HuH} 7$ treated with co-culture media were tested for viability using the MTT. Briefly, cells were plated in 96-well tissue culture plates in a range of $10^{3}$ $10^{5} \mathrm{cells} /$ well in a final volume of $100 \mu \mathrm{L}$ of medium and were allowed to attach overnight at $37^{\circ} \mathrm{C}$. The MTT reagent is added $(20 \mu \mathrm{L}$ per well of $5 \mathrm{mg} / \mathrm{ml}$ MTT) and the plate is incubated for $4 \mathrm{~h}$ to allow for intracellular reduction of the soluble yellow MTT to the insoluble purple formazan dye. Media were removed and $200 \mu \mathrm{L}$ detergent reagents (DMSO) were added to solubilize the formazan dye the absorbance of each sample was read in a microplate reader at 550-600 nm. Six wells were used for each group. Cell proliferation was assessed as the percentage of cell proliferation compared to untreated $\mathrm{HuH} 7$ as control cells.

\section{Biochemical study}

$\alpha$ fetoprotein ( Tumor marker) by ARCHIETECR AFP were measured by Abbott Ireland. Serum albumin, serum liver enzymes such as alanine aminotransferase (GPT or ALT), aspartate aminotransferase (GOT or AST), ALP, and $\gamma-$ GTwere detected by Roche cobas integra, USA.

\section{Real-time quantitative PCR analysis}

cDNA was generated from $5 \mu \mathrm{g}$ of total RNA extracted with $1 \mu \mathrm{L}(20 \mathrm{pmol})$ antisense primer and $0.8 \mu \mathrm{L}$ superscript AMV reverse transcriptase at $25^{\circ} \mathrm{C}$ for $10 \mathrm{~min}, 37^{\circ} \mathrm{C}$ for $120 \mathrm{~min}$ and $85^{\circ} \mathrm{C}$ for $5 \mathrm{~min}$ and finally $4^{\circ} \mathrm{C}$ to infinity. The relative abundance of mRNA species was assessed using the SYBR ${ }^{\circledR}$ Green method on an ABI prism 5700 fast (Applied Biosystems, Foster City, CA, USA). PCR primers were designed with Gene Runner Software (Hasting Software, Inc., Hasting, NY) from RNA sequences from GenBank (Table 1). All primer sets had a calculated annealing temperature of $60^{\circ}$. Quantitative RT-PCR was performed in duplicate in a $20 \mu \mathrm{L}$ reaction volume consisting of $2 X$ SYBR Green PCR Master Mix (Applied Biosystems), $900 \mathrm{nM}$ of each primer and $2-3 \mu \mathrm{L}$ of cDNA. Amplification conditions denaturation at $95{ }^{\circ} \mathrm{C}$ for $15 \mathrm{~min}$,followed by 45 cycles each cycle $94^{\circ} \mathrm{C}$ for $15 \mathrm{sec}, 60^{\circ} \mathrm{C}$ for $25 \mathrm{sec}$ and $72^{\circ} \mathrm{C}$ for $20 \mathrm{sec}$. Data from real-time assays were calculated using the v1.7 Sequence Detection Software from PE Biosystems (Foster City, CA, USA). Relative expression of Survivin PCNA, $\beta$ Catenin, and Telomerase and VEGF mRNA was calculated using the comparative $\mathrm{Ct}$ method as previously described. All values were normalized to the glyceraldehyde-3-phosphate dehydrogenase (GAPDH) gene and reported as fold change $(\Delta \Delta \mathrm{CT})$ over background levels detected in $\mathrm{HuH7}$ group.

\section{Statistical analysis}

The statistical analysis in this study was performed using the following programs: IBM SPSS 22.0.0.2. Python Programming language 2.7.14, python packages (Pandas 0.20.3 and SciPy 0.19.

\section{RESULTS}

In the present study, the hepatoma cell line $\mathrm{HuH} 7$ was chosen as a model for liver cancer. The main objective of the study was to evaluate the effect of two different media, conditioned media (the medium in which umbilical cord mesenchymal cells were cultured) and co-culture medium (the medium in which mesenchymal and $\mathrm{HuH} 7$ cells were cultured) on different parameters in $\mathrm{HuH} 7$ cultured cells. Mesenchymal stem cells from cord (Wharton's jelly) 
were also investigated at $0,3,10$ and 14 days from culturing where the cells reached $95-100 \%$ confluence after 14 days (Figure 1).
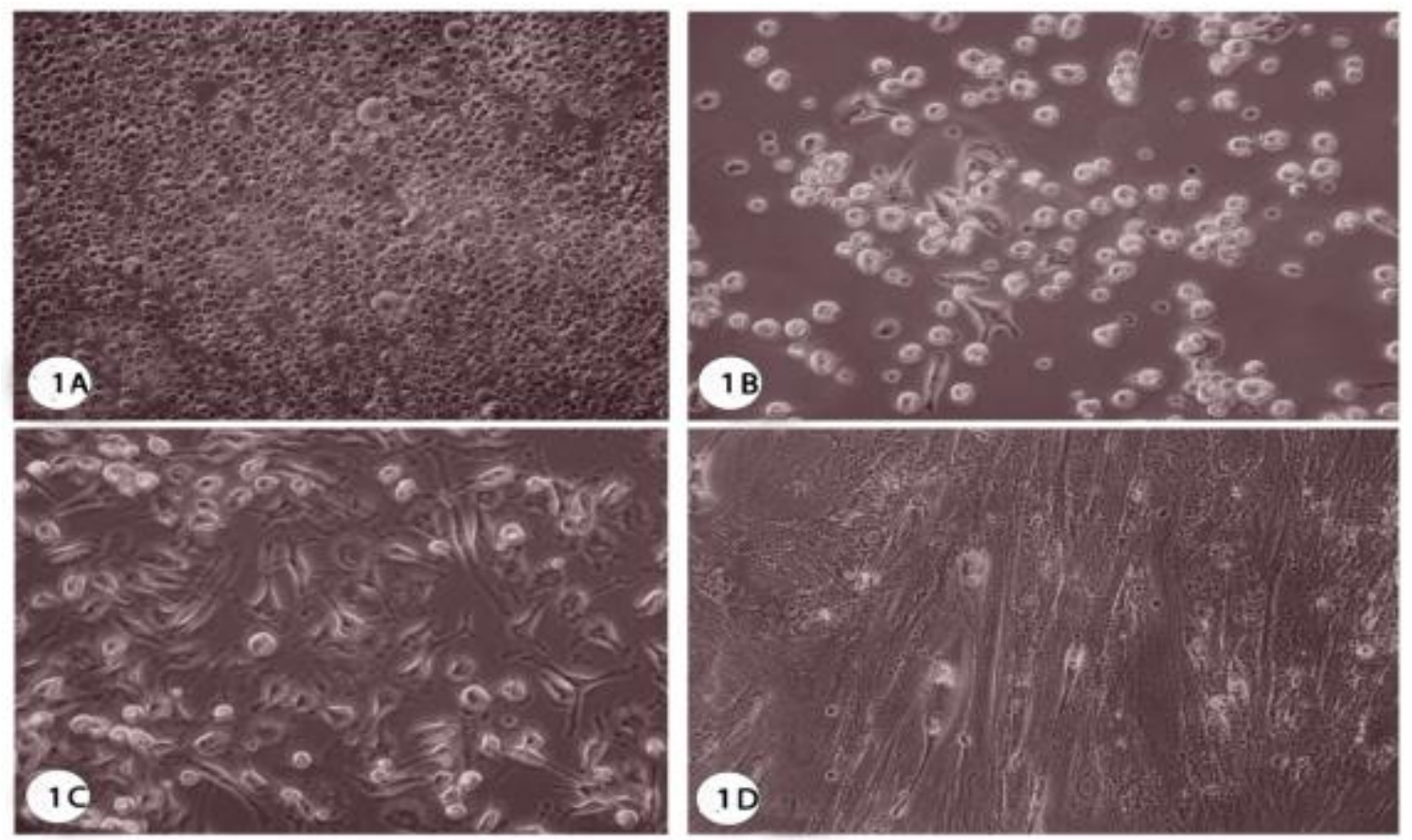

Figure 1: hoto micrographs showing growth of mesenchymal stem cells from cord (Wharton's jelly) (Inverted microscope, X400). A- In 0 time from culture, B- 3 days after changing media, C- 10 days from culture, D- 14 days showing $95-100 \%$ confluence of cells

\section{Morphological characterization}

After treatment of $\mathrm{HuH7}$ cells with conditioned media (Figure 2), for $48 \mathrm{~h}$ number of dead cells were and they were changed in shape. After $72 \mathrm{hrs}$, the number of dead cells increased and cells were damaged while, after 96hrs larger number of dead cells was observed.

After treatment of $\mathrm{HuH} 7$ cells with co-culture media (figure 3 ), for $48 \mathrm{hrs}$ a number of dead cells appeared and cells were damaged, after $72 \mathrm{hrs}$ the number of dead cell increased and cells were more dissociated while, after 96hrs most of the cells appeared dead and severely damaged.
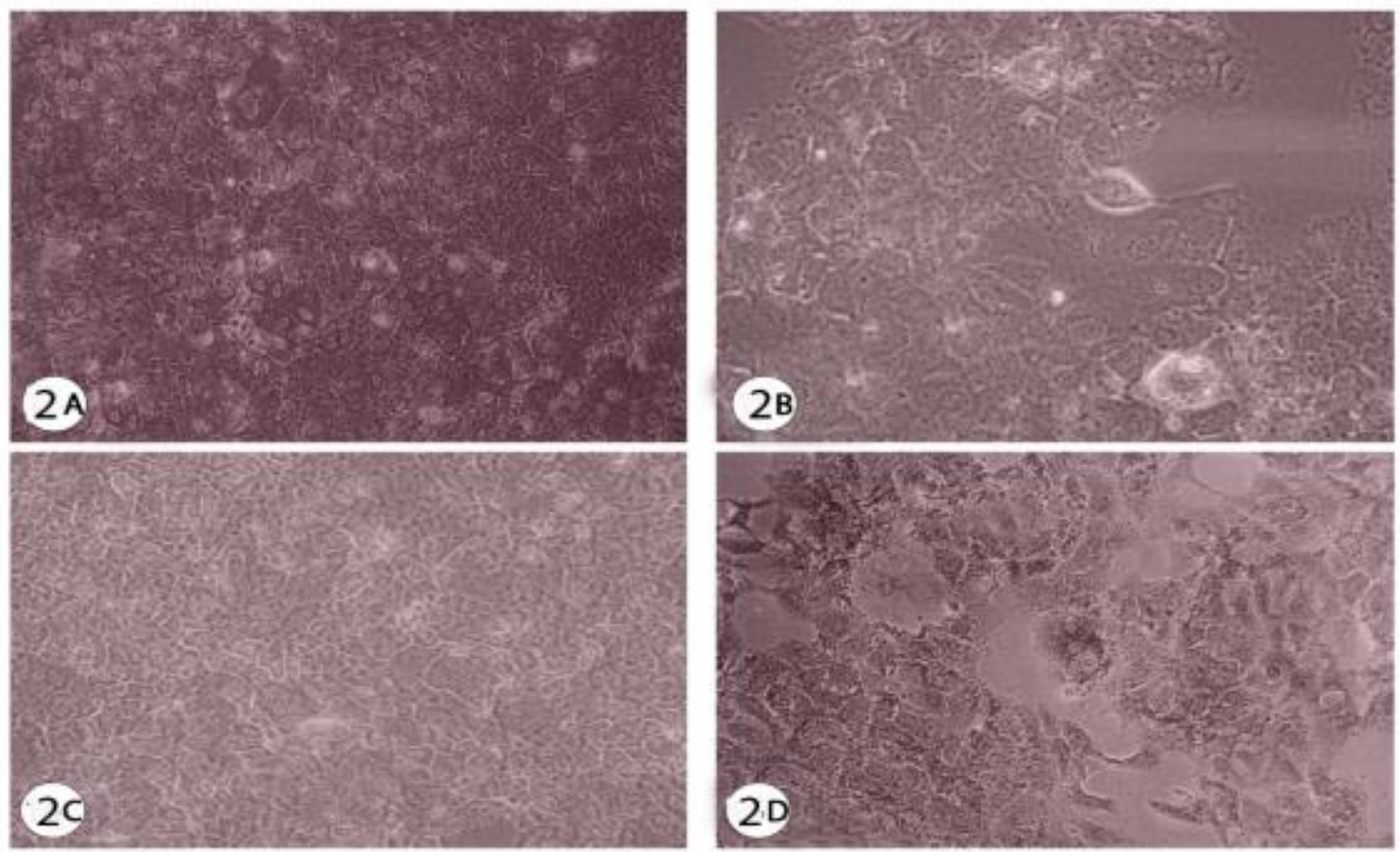

Figure 2: photomicrographs showing effect of conditional media on hepatocellular carcinoma (HuH7) (Inverted microscope, X400). A-Control (confluent HuH7), B- 48 hours after treatment, C- 72 hours after treatment, D-96 hours after treatment 

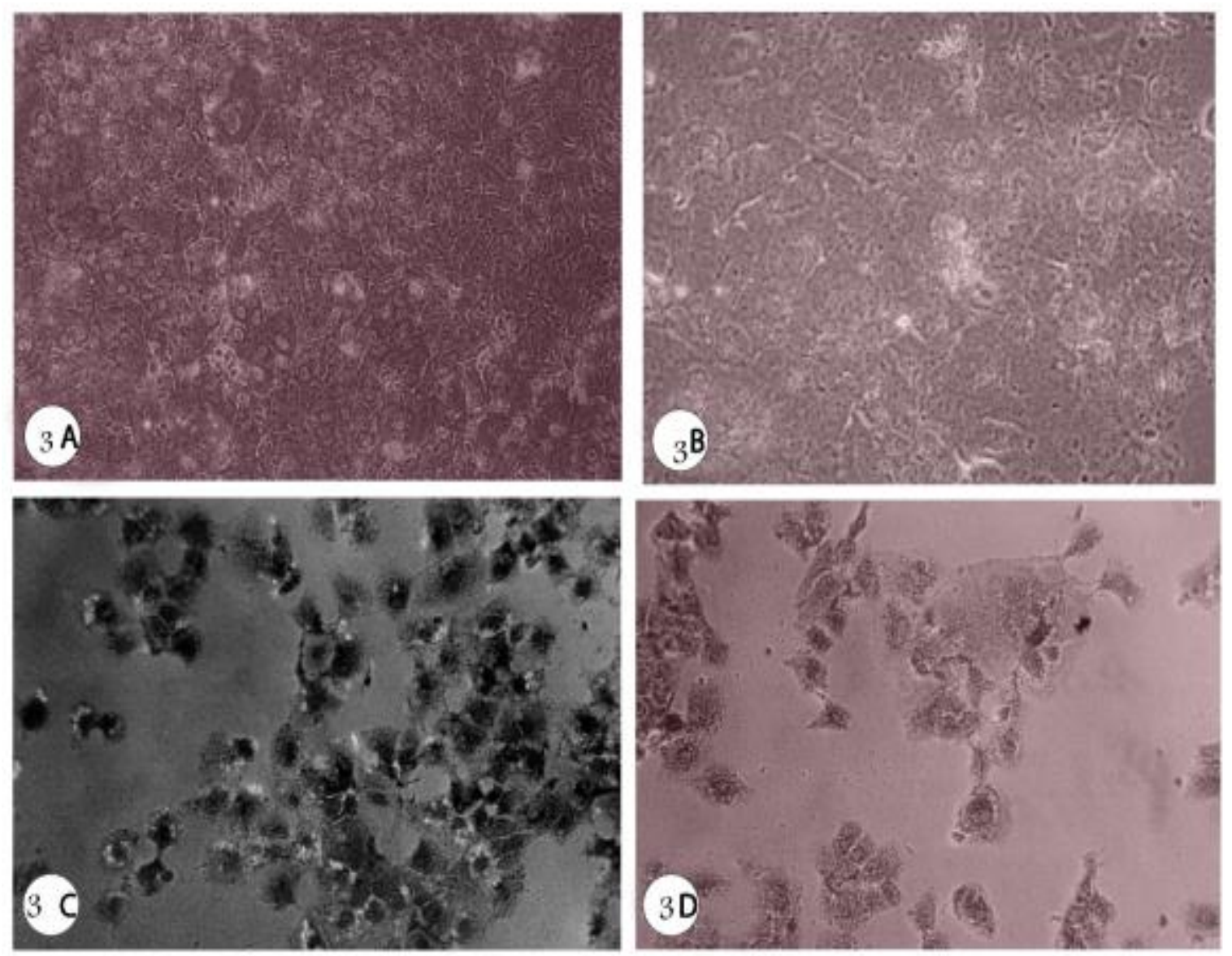

Figure 3: photomicrographs showing effect of co-culture media on hepatocellular carcinoma (HuH7) (Inverted microscope, X400). (A) Control (confluent HuH7), B) 48 hours after treatment, (C) 72 hours after treatment, (D) 96 hours after treatment.

\section{Cell Viability assay (MTT)}

By using the MTT assay, it was found that there were highly significant differences in the viability between hepatoma cell line (HuH7) cultured in normal media, heptoma cell line (HuH7) cultured in the conditioned media $(\mathrm{p}<0.001)$ and co-culture media $(\mathrm{p}<0.001)$. By comparing the cell viability at the four time intervals regarding the non - normally distributed variables, there was highly significant difference between the four groups ( 0 time (HuH7 as control), 48,72and 96hrs). The data in the two box plots (Figure 4) showed that the cell viability was inversely proportional with increased time since after $96 \mathrm{hrs}$ the cells showed the lowest value.
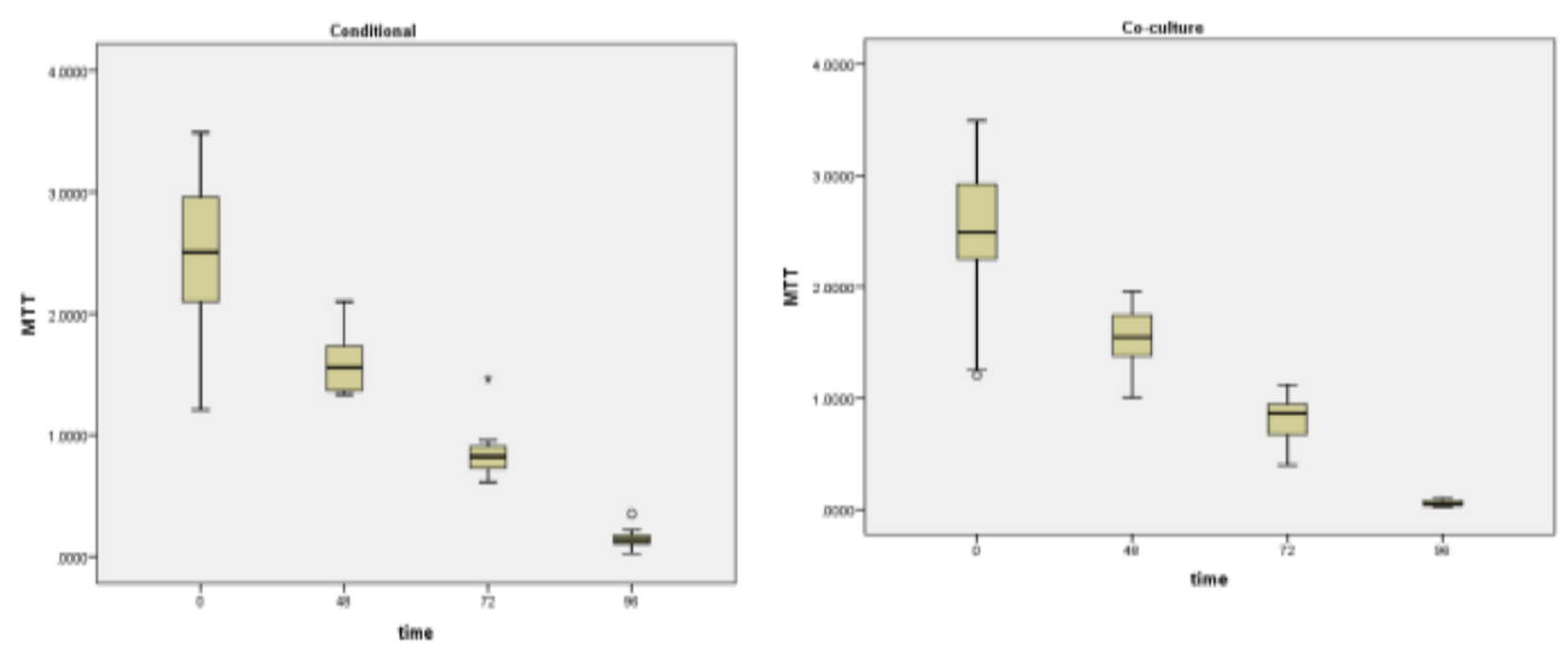
Figure 4: MTT box plot with time for conditioned media and Co-culture media

\section{Biochemical changes in Heptoma Cell Line (HuH7) \\ 3.1 Alfa fetoprotein}

Levels of $\alpha \mathrm{FP}$ in $\mathrm{HuH} 7$ cultured in normal medium and those cultured in conditioned and coculture media changed greatly. There was a highly significant difference between the cases at the different time intervals. By comparing $\alpha \mathrm{FP}$ at the four times in cells cultured in normal media and those cultured in conditioned and co-culture media it was inversely proportional with increase of time since after 96hrs the cells showed the lowest value of $\alpha \mathrm{FP}$.

\subsection{Albumin}

There was non-significant difference in albumin between the two groups (conditioned and coculture groups) $(\mathrm{p}=0.054)$ but, in the conditioned media, comparing the four groups regarding the normally distributed variables, there was a significant difference between the four groups ( 0 time, $48 \mathrm{hrs}, 72$ hrs and 96 hrs.) in albumin ( $p$ value $=0.009$ ). On the other hand, in case of co culture media there was a non-significant difference $(\mathrm{p}=0.650)$ between the four groups.

Table 1: showing normal variable data relation with time in conditioned and co-culture media using ANOVA

\begin{tabular}{|l|l|l|l|}
\hline Test & Media & $\mathbf{f}$ & P value \\
\hline Alfa \\
fetoprotein & Conditioned & 8.359 & $<0.001$ \\
\cline { 2 - 4 } Albumin & Co-culture & 6.914 & 0.01 \\
\cline { 2 - 4 } & Conditioned & 4.401 & 0.009 \\
\hline \multirow{2}{*}{ GOT } & Conditure & 0.591 & 0.650 \\
\cline { 2 - 4 } & co-culture & 29.012 & $<0.001$ \\
\hline
\end{tabular}

\subsection{Liver enzymes (GOT and GPT)}

There was a highly significant difference between the four groups (0-time, $48 \mathrm{hrs}, 72 \mathrm{hrs}$ and $96 \mathrm{hrs}$ ) in GOT activity in case of groups cultured in conditioned media $(p<0.001)$ and those cultured in co-culture media $(\mathrm{p}<0.001)$.There was no significant difference between the four groups ( 0 -time, $48 \mathrm{hrs}, 72 \mathrm{hrs}$ and 96 hrs) in GpT activity since in case of groups cultured in conditioned media ( $p$ value was $<0.674$ ) and those cultured in co-culture media ( $\mathrm{p}$ value was <0.674).

\subsection{Alkaline phosphatase}

Comparing the four groups regarding the nonnormally distributed variables, there was a nonsignificant difference between the four groups (0time, $48 \mathrm{hrs}, 72 \mathrm{hrs}$ and $96 \mathrm{hrs}$ ) neither in case of HuH7 cells cultured in conditioned media ( $p$ value $=$ 0.294 ) nor in case of culturing in co- culture media ( $p$ value $=0.127$ ).

Table 2: showing comparison between the four groups regarding the non-normally distributed variables in two media by using Kruskal-Wallis Test

\begin{tabular}{|l|l|l|l|}
\hline Test & Media & $\begin{array}{l}\text { Chi- } \\
\text { Squared } \\
\text { (df=3) }\end{array}$ & P value \\
\hline GPT & Conditioned & .12616 & $<0.674$ \\
\cline { 2 - 4 } & co-culture & .11286 & $<0.674$ \\
\hline $\begin{array}{l}\text { Alkaline } \\
\text { phosphatase }\end{array}$ & Conditioned & 3.712 & 0.294 \\
\cline { 2 - 4 } & co-culture & 5.706 & 0.127 \\
\hline
\end{tabular}

\subsection{YGT:}

By comparing the two groups regarding the non-normally distributed variables, there was a nonsignificant difference between the two groups (conditioned and co-culture groups) in VGT ( $\mathrm{p}$ value was 0.844).

Table 3: comparing the two groups regarding the non-normally distributed variables by using Mann-Whitney $\mathrm{U}$ test

\begin{tabular}{|c|c|c|c|c|c|c|c|c|}
\hline & \multicolumn{3}{|c|}{ Conditional Media } & \multicolumn{3}{|c|}{ Co-culture Media } & $\mathrm{U}$ & p-value \\
\hline Alk Ph & 25.50 & 30.00 & 38.50 & 27.00 & 35.00 & 40.00 & 644.5 & 0.329 \\
\hline
\end{tabular}




\subsection{Real-time quantitative PCR analysis for expression of cancer related genes. \\ 3.6.1 Survivin}

By comparing the four groups regarding the non-normally distributed variables, there was highly significant difference between the four groups (0-time (HuH7 as control ), 48hrs, $72 \mathrm{hrs}$ and $96 \mathrm{hrs}$ ) in Survivn RQ $(\triangle \Delta C T)$ for Conditioned media ( $p$ value was <0.001) and Co-culture media ( $p$ value was $<0.001)$.

\subsubsection{PCNA}

There was a high significant difference between the two groups (conditioned and co-culture groups) in PCNA RQ $(\mathrm{p}<0.001)$. Comparing the four groups regarding the non-normally distributed variables, there was significant difference between the four groups ( $0 \mathrm{hrs}, 48 \mathrm{hrs}, 72 \mathrm{hrs}$ and $96 \mathrm{hrs}$ ) in PCNA RQ for Conditioned media( $p$ value was $<0.001$ ) and in co - culture media ( $\mathrm{p}$ value was $<0.001$ ).

\subsection{3 $\beta$-Catenin}

By Comparing the two groups regarding the nonnormally distributed variables, there was significant difference between the two groups (conditioned and co-culture groups) in $\beta$-Catenin $\mathrm{C}(\mathrm{p}<0.001)$ and $\beta$ Catenin RQ $(\mathrm{p}<0.022)$. Comparing the four groups regarding the non-normally distributed variables, there was significant difference between the four groups ( $0 \mathrm{hrs}, 48 \mathrm{hrs}, 72 \mathrm{hrs}$ and $96 \mathrm{hrs})$ in $\beta$-Catenin RQ for Conditioned media ( $\mathrm{p}$ value was $<0.001$ ) and in co - culture media( $\mathrm{p}$ value was $<0.001$ ).

\subsubsection{Telomerase}

By Comparing the two groups regarding the non-normally distributed variables, there was nonsignificant difference between the two groups (conditioned and co-culture groups) in telomerase $\mathrm{C}$ $(\mathrm{p}=0.617)$ and telomerase RQ $(\mathrm{p}=0.611)$. Comparing the four groups regarding the non-normally distributed variables, there was significant difference between the four groups $(0 \mathrm{hrs}, 48 \mathrm{hrs}, 72 \mathrm{hrs}$ and 96 hrs) in telomerase RQ for Conditioned media ( $p$ value was $<0.001)$ and in co - culture media( $\mathrm{p}$ value was $<0.001)$.

\subsubsection{VEGF}

By Comparing the two groups regarding the non-normally distributed variables, there was significant difference between the two groups (conditioned and co-culture groups) VEGF RQ $(\mathrm{p}<0.001)$. Comparing the four groups regarding the non-normally distributed variables, there was significant difference between the four groups $(0 \mathrm{hrs}$, $48 \mathrm{hrs}, 72 \mathrm{hrs}$ and $96 \mathrm{hrs}$ )in VEGF RQ for Conditioned media ( $p$ value was $<0.001$ ) and in co - culture media ( $\mathrm{p}$ value was $<0.001$ ).

Table 4: showing comparison between the four groups regarding the non-normally distributed variables in two media by using Kruskal-Wallis Test

\begin{tabular}{|l|l|l|l|}
\hline Gene & Media & $\begin{array}{l}\text { Chi- } \\
\text { Squared } \\
\text { (df=3) }\end{array}$ & P value \\
\hline Survivin & Conditioned & 40.974 & $<0.001^{* *}$ \\
\cline { 2 - 4 } & co-culture & 40.986 & $<0.001^{* *}$ \\
\hline PCNA & Conditioned & 40.977 & $<0.001^{* *}$ \\
\cline { 2 - 4 } & co-culture & 40.846 & $<0.001^{* *}$ \\
\hline \multirow{3}{*}{-Catenin } & Conditioned & 40.969 & $<0.001^{* *}$ \\
\cline { 2 - 4 } & co-culture & 40.983 & $<0.001^{* *}$ \\
\hline Telomerase & Conditioned & 39.974 & $<0.001^{* *}$ \\
\cline { 2 - 4 } & co-culture & 40.98 & $<0.001^{* *}$ \\
\hline VEGF & Conditioned & 41.015 & $<0.001^{* *}$ \\
\cline { 2 - 4 } & co-culture & 36.921 & $<0.001^{* *}$ \\
\hline
\end{tabular}

\section{DISCUSSION}

In the present study, the effect of conditioned media and co-culture media on cultured $\mathrm{HuH} 7$ cells was studied by measuring; morphological changes, cell viability, certain biochemical changes, expression of cancer- related genes.The results of this study showed morphological changes and dramatic decrease in cell viability which were all time dependent on the number of dead $\mathrm{HuH7}$ cells which were cultured in conditioned media and co-culture media. El-nahrawy et al. ${ }^{(6)}$ showed morphological changes and possible beneficial effect of human umblical cord MSCsconditioned media on liver malignant cells HepG2 via the secretion of soluble factors or cytokines like IL-10 having anti-inflammatory and possible anti-tumor effects. Ramasamy et al. ${ }^{(7)}$ studied the effect of MSC on the proliferative activity of malignant cells of different lineages. The tumor cell lines of hematopoietic (BV173, K562, Jurkat, KG1a and wS9B-LCL) and non-hematopoietic (UCH10 and CC3) origin were cultivated, at different ratios, in the presence of MSC and tested for their proliferative activity after 3 days of co-culture. MSC exhibited a dose-dependent anti-proliferative effect on all cell lines investigated. Alpha-fetoprotein $(\alpha \mathrm{FP})$ is a good tumor marker that is elevated in $60-70 \%$ of patients with hepatocellular carcinoma. Normally, levels of $\alpha \mathrm{FP}$ are below $10 \mathrm{ng} / \mathrm{ml}$, but marginal elevations (10100) are common in patients with chronic hepatitis. The progressive elevation of alpha fetoprotein $\geq 7$ $\mathrm{ng} / \mathrm{mL} /$ month in patients with liver cirrhosis is useful for the diagnosis of hepatocellular carcinoma in patients that do not reach $\alpha \mathrm{FP}$ levels $\geq 200 \mathrm{ng} / \mathrm{mL}^{(\mathbf{8})}$. Also, the serum concentration of $\alpha \mathrm{FP}$ is often elevated in patients with HCC. $\alpha \mathrm{FP}>400 \mathrm{ng} / \mathrm{ml}$ is considered diagnostic for $\mathrm{HCC}$, although less than half of patients with $\mathrm{HCC}$ may generate that high levels of $\alpha \mathrm{FP}^{\left({ }^{(9)}\right.}$. On the contrary, some investigations showed that $\alpha \mathrm{FP}$ cannot be used in the initial screening of HCC due to its low sensitivity at diagnostic values. There may be elevation of $\alpha \mathrm{FP}$ in patients with chronic $\mathrm{HCV}$ infection and may be normal in patients with HCC. The findings are consistent with American 
Association for Study of Liver Diseases (AASLD) guidelines which recommend only abdominal ultrasound for screening, but against the Asia Pacific Association for study of Liver Diseases (APASL) guidelines which recommend both $\alpha \mathrm{FP}$ levels and abdominal ultrasound ${ }^{(\mathbf{1 0})}$. The previous study also suggested that normal $\alpha \mathrm{FP}$ levels should always be supported by sensitive imaging technique before excluding HCC. In the present study $\alpha \mathrm{FP}$ values were inversely proportional with the increase of time of incubation of $\mathrm{HuH} 7$ cells whether in conditioned media or co- culture media as they showed highly significant decrease since lowest values were recorded after $96 \mathrm{hrs}$.In clinical practices, liver functions have long been considered to assume crucial status in the prognosis of many types of cancers such as gallbladder and colorectal cancers. Liver functions can be reflected by markers not only like ALB, GELO, and TP, indicators of the nutritional status, but also like ALP, ALT, AST, $\gamma-$ GT, LDH, TBIL, and DBIL, indices reflecting liver damage. All these liver function parameters were firstly evaluated for their effect on the overall survival in intrahepatic cholangiocarcinoma (ICC) patients. Therefore, these liver enzymes may serve as valuable predictive markers in ICC patients ${ }^{(11)}$.To date; studies have shown that abnormal changes of liver enzymes often lead to poor prognosis in a multitude of cancers. Likewise, other liver function markers such as ALP and gamma-glutamyltranspeptidase $(\mathrm{Y}-\mathrm{GT})$ were often risk factors in patients with some types of cancers ${ }^{(12)}$.

In the present study it was found that ALP did not show any significant change in case of using co-culture media or conditioned media from 0 time until 96hrs. In tissue, ALP is well known as a membrane-bound ectoenzyme, used as an indicator to reflect hepatobiliary or bone diseases and that it is attached to the membrane via a glycan phosphatidylinositol (GPI) anchor ${ }^{(13)}$. Numerous studies demonstrated that cytokeratin (CK) and enzyme gamma-glutamyl transferase $(\gamma \mathrm{GT}){ }^{\left({ }^{(14)}\right.}$ may be altered in cancers. The ability of tumor cells of hepatocellular origin to express a biliary cytokeratin profile may contribute to the very high levels of $\gamma \mathrm{GT}$ in $\mathrm{HCC}^{(15)}$.

The data of Moreira et al. ${ }^{(16)}$ supported the clinical observations recorded in numerous clinical studies that described the close relationship between the worsening of hepatocellular carcinoma with increased $\gamma \mathrm{GT}$ levels. The data of the present study showed highly significant decrease in the level of $\gamma \mathrm{GT}$ with the increase of incubation time from $0-$ $96 \mathrm{hrs}$ in case of using conditional media or co-culture media for treatment of $\mathrm{HuH7}$ cells, which means according to the report of Moreira $\boldsymbol{e t}$ al. ${ }^{(16)}$ that these media have antitumor effect. The present data showed lower levels of GOT and GPT after the incubation in conditional media or co-culture media at $48,72,96$ hrs. It is worthy to mention that Hijona et al. (17) observed significantly lower levels of GOT, GPT, YGT and ALP in rats with induced hepatocellular carcinoma treated with chemotherapeutic drugs( Pravastatin and Sorafenib).

This confirms the conception that conditioned media and co-culture media have antitumor effect in the present study. Survivin which is considered as an inhibitor of apoptosis protein, is highly expressed in most cancers and associated with chemotherapy resistance, increased tumor recurrence, and shorter patient survival, making antisurvivin therapy an attractive cancer treatment strategy. Strong survivin expression was observed in the vast majority of cancers. These included esophageal, lung, ovarian, central nervous system, breast, colorectal, bladder, gastric, prostate, pancreatic laryngeal, uterine, hepatocellular, and renal cancers, as well as melanoma

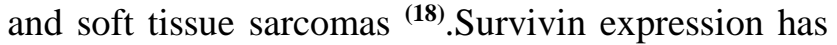
been recognized as a biomarker; high expression indicated an unfavorable prognosis and resistance to chemotherapeutic agents and radiation treatment ${ }^{(19)}$. Several antisurvivin preclinical trials in solid tumor models showed that disrupting survivin can reduce tumor growth ${ }^{(20)}$.

In the present study survivin gene is expressed at a very high rate at the beginning of experiment (0-time) when $\mathrm{HuH} 7$ cells were incubated in conditioned media and co-culture media and decreased significantly with the increase of time to 96 hrs where it showed the lowest expression. We detected in the morphological studies the antitumor effect of these media on $\mathrm{HuH} 7$ cells. The proliferating cell nuclear antigen (PCNA) is a nuclear protein which was independently discovered by Miyachi $\boldsymbol{e t}$ al. ${ }^{\text {(21) }}$ as PCNA and by Bravo and Celis ${ }^{(22)}$ as cyclin, later it has been identified as the co-factor of DNA polymerase delta ${ }^{(23) \text {. }}$

PCNA is the very heart of many essential cellular processes such as DNA replication, repair of DNA damage, chromatin structure maintenance, chromosome segregation and cell-cycle progression and can be regarded as one of their common integrators ${ }^{(24)}$. The increased expression of PCNA could also have a predictive and prognostic value. However, the value of PCNA as a biomarker remains controversial (25).

Mun et al. ${ }^{(26)}$ found that more "diseased" livers, neoplastic and non-neoplastic, expressed PCNA than "normal, undiseased livers". Nevertheless, PCNA was also expressed by 2 of twenty normal livers. The reason for this is unclear but other studies have also recorded PCNA expression in normal livers. 
Recently, Qiu et al. ${ }^{(27)}$ concluded that expression of PCNA, Ki-67 and COX-2 is a significant predictor for the occurrence, invasion and metastasis of breast invasive ductal carcinoma.The present study showed that there was شsignificant difference between the two groups (conditioned and co-culture groups) in PCNA (p value was $<0.001$ ). By comparing the four groups (0-time, 48-hrs, 72-hrs and 96-hrs) it was noticed that PCNA expression was inversely proportional with increase of time but in case of using conditioned media a fluctuation happened at $48 \mathrm{hrs}$. Then a steady decrease continued. Thus, it can be said that the media used in our experiments might have anti proliferative effect by reducing PCNA expression which seems to coincide with the opinion of Qiu et al. ${ }^{\text {(27). }}$.

Liver cancer is highly heterogeneous and involved deregulation of several signaling pathways. $\mathrm{Wnt} / \beta$-catenin pathway is frequently upregulated in $\mathrm{HCC}$ and it is implicated in maintenance of tumor initiating cells, drug resistance, tumor progression, and metastasis. A great effort in developing selective drugs to target components of the $\beta$-catenin pathway with anticancer activity is underway, but only few of them have reached phase clinical trials ${ }^{(28)}$.

Activation of the Wnt/b-catenin pathway has been observed in at least $1 / 3$ of hepatocellular carcinomas (HCC) and a significant difference of these have mutations in the b-catenin gene. Therefore, effective inhibition of this pathway could provide a novel method to treat $\mathrm{HCC}^{(\mathbf{2 9})}$. Fifty percent of HCC that express c-myc or H-ras in the liver contain bcatenin mutations. de La Coste et al. ${ }^{(30)}$ suggested that b-catenin activation can cooperate with ras or myc in HCC progression. Moreover, b-catenin mutations and exon 3 deletions have been identified in $48 \%$ of sporadic hepatoblastomas. The present study also showed a non significant difference in $\beta$-catenin between the two groups of $\mathrm{HuH} 7$ cultured in conditioned and co-culture media.

Also there was a significant difference decrease between the four groups (0-time, 48-hrs, 72hrs and 96-hrs) and the lowest value was seen after 96 hrs, which indicates to the inhibition of $\beta$-catenin in hepatoma cell line $\mathrm{HuH} 7$ during this kind of treatment with media. Telomere shortening may represent a "mitotic clock" associated with cellular senescence. Telomerase is a ribonucleoprotein enzyme that catalyzes the synthesis of telomeric DNA.

It therefore, helps in the formation and protection of telomere and also prevents cells from undergoing senescence ${ }^{(31)}$. Telomerase became an attractive potential drug target in the fight against cancer owing to its low/absent expression levels in normal somatic cells and high expression in cancer. Detection of telomerase activity has been proposed to be a useful tool in the diagnosis of pancreatic cancer (32). Recently abnormal activation of telomerase was found to occur in 85-90\% of all cancers and support the ability of cancer cells to bypass their proliferative limit, rendering them immortal ${ }^{(33)}$.

The present study showed that there was a highly significant difference between the four groups of culturing times (0-time, 48hrs, 72-hrs and 96-hrs) in telomerase RQ in case of using conditioned media $p$ value was $(p<0.001)$ and in co-culture media was $(\mathrm{p}<0.001)$ and the general scope is gradual decrease with the increase of time. This indicates to the ability of these media to be used as anticancer therapeutics but further studies are needed. VEGFs mediate a plethora of biological processes in the endothelial cells such as cell proliferation, migration, survival, cell-cell communication, and differentiation. Some VEGFs also regulate vessel permeability.

Signaling pathways activated by VEGFs play fundamental roles in the de novo formation of vessels from hematopoietic precursor cells, a process called vasculogenesis and in angiogenesis, formation of vessels from pre-existing vasculature ${ }^{(34)}$. An animal model has shown that VEGF augments HCC development and metastasis, and VEGF overexpression has been reported in $\mathrm{HCC}$ and surrounding liver. Circulating VEGF concentrations have been found to increase according to HCC stage (35). Nagy et al. (35) investigated the relationship between VEGF gene polymorphisms and the prognosis of HCC patients. This study is the first to show that VEGF polymorphisms may be significant genetic markers for HCC prognosis. In the present study, results indicated that VEGF expression levels in conditioned media and co-culture media were significantly different and that an obvious decrease dependent with time in VEGF expression levels was recorded in both kinds of media.

At 0-time VEGF expression level was high and decreased gradually and reached lowest value after $96 \mathrm{hrs}$.

\section{CONCLUSION}

The present work showed the potential clinical applications of conditional media and co-culture media of human UCMSCs on a model of HCC. Genetic study investigations affirmed that future studies should focus on determining the role played by exosomes and their potential diagnostic and therapeutic benefits in cancer treatments. Biochemical results and gene expression analysis supported the conception that conditioned and co-culture media greatly suppressed and structurally damaged cancer cells.

\section{REFERENCES}

1. GLOBOCAN (2002): Cancer Incidence and Mortality Worldwide. International Agency for Research on Cancer (IARC). http://www-dep.iarc.fr. Accessed 2002. 
2. El-Serag HB (2001): Epidemiology of hepatocellular carcinoma. Clin. Liver Dis., 5:87-107.

3. Polaniak R, Bułdak RJ, Jacheć W et al. (2011): Longterm exposure to acetaminophen is a crucial for activity of selected antioxidative enzymes and level of lipid peroxidation process in rat Liver. J. Bioequiv. Availab., 3: 182-186.

4. Greenbaum LE and Wells RG (2011): The role of stem cells in liver repair and fibrosis. Int. J. Biochem. Cell Biol., 43: 222-229.

5. Donald G and Phinney MF (2017): Concise review: MSC- derived Exosomes for cell- free therapy. Stem Cells, 35:851-858.

6. EL-nahrawy HH, Mohamed ME, EL-desoky MA et al. (2016): Immunomodulatory effect of human umbilical cord blood-derived mesenchymal stem cells on hepatocellular carcinoma cell lines (HepG2). Med. J., 84 (2): 33-37.

7. Ramasamy R, Lam E, Soeiro I et al. (2007): Mesenchymal stem cells inhibit proliferation and apoptosis of tumor cells: impact on in vivo tumor growth. Leukemia, 21: 304-310.

8. Arrieta O, Cacho B, Morales-Espinosa D et al. (2007): The progressive elevation of alpha fetoprotein for the diagnosis of hepatocellular carcinoma in patients with liver cirrhosis. BMC Cancer, 7:28.

9. Colombo M (2001): Screening for cancer in viral hepatitis. Clin. Liver Dis., 5:109-131.

10.Shah SMA, Butt $Z$ and Waqas $M$ (2017): Alpha fetoprotein; useful as screening test for hepatocellular carcinoma due to chronic hepatitis C. Professional Med. J., 24(5):641-645.

11.Zhang C, Wang $H$, Ning $Z$ et al. (2017): Serum liver enzymes serve as prognostic factors in patients with intrahepatic cholangiocarcinoma. Onc. Targets and Therapy, 10: 1441-1449.

12.Zhang MH, Tang LB, Zhang $X$ et al. (2014): $\gamma$ Glutamyltranspeptidase is a prognostic marker of survival and recurrence in radiofrequency-ablation treatment of hepatocellular carcinoma. Ann. Surg. Oncol., 21(9):30843089.

13. Moss DW (1992): Perspectives in alkaline phosphatase research. Clin. Chem., 38:2486-2492.

14. Roomi MW, Lee G and Faber E (1987): Expression of serum and hepatic $\gamma$-glutamyl transferase $(\gamma$-GT) activities during carcinogenic process in resistant hepatocyte $(\mathrm{R}-\mathrm{H})$ model in rat. Clin. Biochem ., 20(4):296-311.

15. Van Eyken PL, Sciot R, Paterson A et al. (1988): Cytokeratin expression in hepatocellular carcinoma: an immunohistochemical study. Hum. Pathol., 19:562-568

16. Moreira AJ, Rodrigues R, Janz A et al. (2017): Ductular reaction, cytokeratin 7 positivity, and gamma-glutamyl transferase in multistage hepatocarcinogenesis in rats. Protoplasma., 254:911-920

17.Hijona E, Banales JM, Hijona L et al. (2012): Pravastatin inhibits cell proliferation and increased MAT1A expression in hepatocarcinoma cells and in vivo models .Cancer Cell International, 12:5-8.

18. Fukuda $S$ and Pelus LM (2006) : Survivin, a cancer target with an emerging role in normal adult tissues. Mol. Cancer Ther., 5(5):1087-1098.
19. Groner B and Weiss A (2014): Targeting Survivin in cancer: novel drug development approaches. Bio. Drugs, 28:27-39.

20.Mesri M, Morales-Ruiz M, Ackermann EJ et al. (2001): Suppression of vascular endothelial growth factormediated endothelial cell protection by survivin targeting. Am. J. Pathol., 158:1757-1765.

21.Miyachi K, Fritzler M J and Tan EM (1978): Autoantibody to a nuclear antigen in proliferating cells. J. Immun., 121: 2228-2234.

22. Bravo R, Celis JE (1980): A search for differential polypeptide synthesis throughout the cell cycle of HeLa cells. J. Cell Biol., 84:795-802.

23. Bravo R, Frank R, Blundell PA et al. (1987): Cyclin/PCNA is the auxiliary protein of DNA polymerasedelta. Nature, 328: 515-517.

24.Stoimenov I, Helleday T (2009): PCNA on the crossroad of cancer. Biochem. Soc. Trans., 37: 605-613.

25. Lindström MS and Wallin KL (2006): Prognostic role of proliferating cell nuclear antigen (PCNA) in cancer and other diseases. Proliferating Cell Nuclear Antigen, 81: 969 .

26. Mun K, Cheah P, Baharudin NB et al. (2006): Proliferating cell nuclear antigen (PCNA) activity in hepatocellular carcinoma, benign peri-neoplastic and normal liver. Malaysian J. Pathol., 28(2): 73 - 77.

27. Qiu X, Mei J, Yin J et al. (2017): Correlation analysis between expression of PCNA, Ki67 and COX-2 and X-ray features in mammography in breast cancer. Oncology Letters, 14: 2912 -2918.

28. Vilchez V, Turcios L, Marti F et al. (2016): Targeting Wnt/ $\beta$-catenin pathway in hepatocellular carcinoma treatment . World J. Gastroenterol., 22(2): 823-832.

29. Gedaly R, Galuppo R, Daily MF et al. (2014): Targeting the Wnt/b-Catenin signaling pathway in lLiver cancer stem cells and hepatocellular carcinoma cell lines with FH535 . PLoS ONE, 9(6): 99272-99283.

30.de La Coste A, Romagnolo B, Billuart $P$ et al. (1998): Somatic mutations of the b-catenin gene are frequent in mouse and human hepatocellular carcinomas. Proc. Natl. Acad. Sci. USA., 95:8847-8851.

31.Zisuh AV, Han TQ and Zhan SD (2012): Expression of telomerase and its significance in the diagnosis of pancreatic cancer. Indian J. Me. Res., 135: 26-30.

32. Ohuchida K, Mizumoto K, Ogura Y et al. (2005): Quantitative assessment of telomerase activity and human telomerase reverse transcriptase messenger RNA levels in pancreatic juice samples for the diagnosis of pancreatic cancer. Clin. Cancer Res., 77: 2285-2292.

33.Armstrong CA and Tomita K (2017): Fundamental mechanisms of telomerase action in yeasts and mammals: understanding telomeres and telomerase in cancer cells. Open Biol., 7: 160-168.

34. Cébe-Suarez S, Zehnder-Fjällman $\mathrm{AH}$ and BallmerHofer $K$ (2006): The role of VEGF receptors in angiogenesis; complex partnerships. Cell Mol. Life Sci., 63: 601-615.

35. Nagy JA, Benjamin L, Zeng H et al. (2008): Vascular permeability, vascular hyper permeability and angiogenesis. Angiogenesis, 11: 109-119. 